\title{
Recent advances in semiconductor optical amplifiers and their applications
}

Stubkjær, Kristian; Mikkelsen, Benny; Djurhuus, Torsten; Storkfelt, Niels; Jørgensen, Carsten; Jepsen, Kim Stokholm; Nielsen, Torben Nørskov; Gliese, Ulrik Bo

Published in:

Fourth International Conference on Indium Phosphide and Related Materials

Link to article, DOI:

10.1109/ICIPRM.1992.235594

Publication date:

1992

Document Version

Publisher's PDF, also known as Version of record

Link back to DTU Orbit

Citation (APA):

Stubkjær, K., Mikkelsen, B., Djurhuus, T., Storkfelt, N., Jørgensen, C., Jepsen, K. S., Nielsen, T. N., \& Gliese, U. B. (1992). Recent advances in semiconductor optical amplifiers and their applications. In Fourth International Conference on Indium Phosphide and Related Materials (pp. 242-245). IEEE.

https://doi.org/10.1109/ICIPRM.1992.235594

\section{General rights}

Copyright and moral rights for the publications made accessible in the public portal are retained by the authors and/or other copyright owners and it is a condition of accessing publications that users recognise and abide by the legal requirements associated with these rights.

- Users may download and print one copy of any publication from the public portal for the purpose of private study or research.

- You may not further distribute the material or use it for any profit-making activity or commercial gain

- You may freely distribute the URL identifying the publication in the public portal 


\title{
RECENT ADVANCES IN SEMICONDUCTOR OPTICAL AMPLIFIERS AND THEIR APPLICATIONS
}

\author{
K.E. Stubkjaer, B. Mikkelsen, T. Durhuus, N. Storkfelt, C. Joergensen, K. Jepsen, T.N. Nielsen, U. Gliese \\ Center for Broadband Telecommunications, Electromagnetics Institute, \\ Technical University of Denmark, DK-2800 Lyngby, Denmark.
}

\section{Introduction}

Two types of optical amplifiers are presently being developed: the erbium doped fiber amplifier and the semiconductor optical amplifier (SOA). The erbium doped fiber amplifier has attracted much attention because of impressive performance, but the SOAs performance is improving and it will also become important for a number of applications. The SOA is in principle simpler than the fiber amplifier but it requires very advanced fabrication technology for ideal performance. It is pumped directly by an electrical current and consists of a single component only, leading to a potential lower price. Another advantage is that it lends itself to opto-electronic integration. Further, SOAs with high gain are available both in the 1.3 and $1.55 \mu \mathrm{m}$ wavelength regions.

The SOAs major disadvantage and fundamental difference to the fiber amplifier is its nonlinearity due to a short lifetime of the injected carriers. The interaction between gain and carrier density can on the other hand be used in a number of more sophisticated applications where the SOA serves not only as an amplifier, but also as modulator, gate, frequency converter or detector. Here we review recent advances in SOAs and some of their applications.

\section{Progress in semiconductor optical amplifiers}

The SOA is in principle a semiconductor laser with reduced facet reflectivities. It is, however, important that the gain is polarization independent which is usually not the case for a laser. Therefore the waveguides in amplifiers must be designed for polarization insensitive gain and at the same time for high coupling efficiencies to optical fibers. Some of these aspects are reviewed in this section.

\section{Polarization sensitivity}

Equal gain for TE and TM polarized light requires nearly equal confinement factors for the two polarizations. This is achieved with square shaped buried waveguides [1]-[3]. The cross section of a recently developed Modified Dual Channel Planar Buried Heterostructure (M-DCPBH) waveguide with a width of $0.4 \mu \mathrm{m}$ and a thickness of $0.3 \mu \mathrm{m}$ is shown in Fig. 1a [4]. This structure achieves polarization sensitivities of $0.5 \mathrm{~dB}$ for an internal gain of $28 \mathrm{~dB}$. It should be noted this high gain is obtained for an injection current of less than $100 \mathrm{~mA}$ due to the small cross section of the active guide.

The Ridge Waveguide (RWG) structure with a Separate Confinement Heterostructure ( $\mathrm{SCH}$ ) as shown in Fig. 1b can also achieve a $25 \mathrm{~dB}$ internal gain with a polarization sensitivity smaller than $1 \mathrm{~dB}$ [5]. Control or elimination of the stress that is induced by the dielectric coatings is important to realize polarization insensitive devices. This is also the reason for using proton implantation in the M-DCPBH structure.

\section{Facet reflectivities}

Low residual facet reflectivities are very important for a low gain ripple, as well as for a low noise figure, intermodulation distortion and crosstalk. For a gain ripple less than $1 \mathrm{~dB}$ at $25 \mathrm{~dB}$ of internal gain the residual facet

(A)

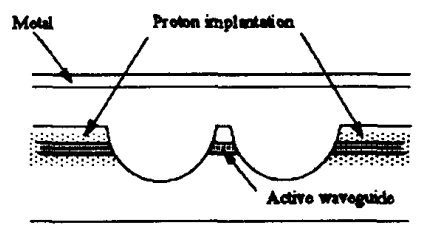

(B)

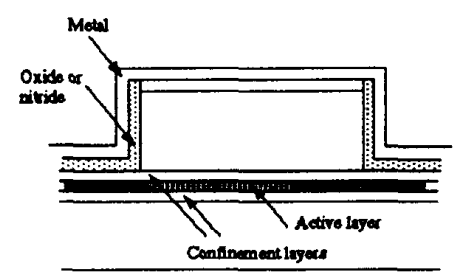

Fig. 1 Cross sections of polarization insensitive SOAs with M-DCPBH structure (A) [4] and RWG SCH structure (B) [5]. 
reflectivity must be less than $2 \cdot 10^{-4}$. Residual reflectivities of this order can easily be produced, but it is important that they are attained in a large optical bandwidth and are independent of polarization.

Three methods for reduction of the reflectivity are shown in Fig. 2. Double layer AR-coatings have been applied to polarization independent straight facet amplifiers. Reflectivities as low as $7 \cdot 10^{-5}$ have been obtained for both polarizations with $\mathrm{TiO}_{2} / \mathrm{SiO}_{2}$ coatings applied to the M-DCPBH structure in Fig. 1a [4].

(A)

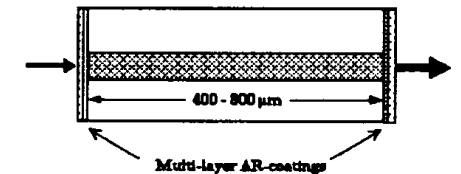

(B)

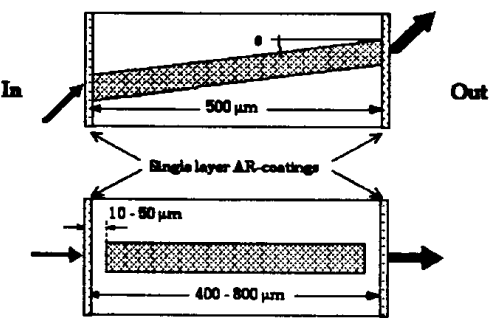

Fig. 2 Top view of nearly travelling wave SOAs: a) Straight facet amplifier with multilayer AR-coatings, b) Angle facet amplifier with single layer AR-coatings, and c) Buried facet amplifier with single layer AR-coatings.

Angling of the waveguide to the facet normal as shown in Fig. $2 b$ is another approach that is well suited for weakly guided structures. RWG SOAs angled at 7 and $10^{\circ}$ and coated with a single layer AR-coating [6] have been fabricated with reflectivities of $3 \cdot 10^{-5}$ and $1 \cdot 10^{-5}$.

Low reflectivities can also be realized with window structures (Fig. 2a) where the active waveguide is terminated in semiconductor material with a matching refractive index [1], [2]. Only a small part of the light coupled through the window sections will be reflected back into the waveguide and residual reflectivities of $2-3 \cdot 10^{-4}$ are reported [2].

\section{Packaging}

Clearly, a high coupling efficiency is important for a high fiber-to-fiber gain. For the polarization insensitive amplifiers with a thick active layer there is a tradeoff between polarization sensitivity and coupling efficiency since the far field becomes wider and the coupling efficiency smal- ler with increasing active layer thickness. The polarization insensitive M-DCPBH structure has coupling efficiencies to tapered lens-ended fibers of $4-5 \mathrm{~dB} /$ facet. Booth high coupling efficiency and low polarization sensitivity may, however, be realized by tapering the thickness the active layer towards the facets [7]. Similarly the angled facet structure has a tradeoff between coupling efficiency and residual facet reflectivity since the far field becomes increasingly asymmetric with larger facet angles. Coupling efficiencies of $3-4 \mathrm{~dB} /$ facet are observed for facet angles of $7-10^{\circ}$. Packaged SOAs with a fiber-tofiber gain of $17-21 \mathrm{~dB}$ have been realized [4], [5], [8].

Work on hybrid packaging of SOAs on silicon substrates is now under way to allow for a higher functionality and packaging density. Ultimately, the amplifiers should be monolithically integrated with other components. As examples, integration of lasers and a booster amplifier has been reported [9] and a $2 \times 2$ switch array with four integrated SOAs has been demonstrated [10].

\section{Multi quantum well amplifiers}

SOAs incorporating multi quantum well (MQW) structures have a number of attractive features compared to bulk devices. Thus, a saturation output power as high as $+20 \mathrm{dBm}$ is reported for MQW-SOAs with an unsaturated gain of $7 \mathrm{~dB}$ [11]. This should be compared to typical values of $+7 \mathrm{dBm}$ for bulk devices. In addition the bandwidth of MQW-SOAs is typically larger than $100 \mathrm{~nm}$.

MQW-SOAs can also exhibit noise figures close to the ideal value of $3 \mathrm{~dB}$, compared to $5-7 \mathrm{~dB}$ for bulk devices [12]. An example of measured and theoretically calculated noise figure versus wavelength is seen in Fig. 3. For practical applications, the input coupling losses will increase the effective noise figure by $3-5 \mathrm{~dB}$.

The major drawback of MQW-SOAs is a high polarization sensitivity. This can, however, be reduced or eliminated by strained layers [13].

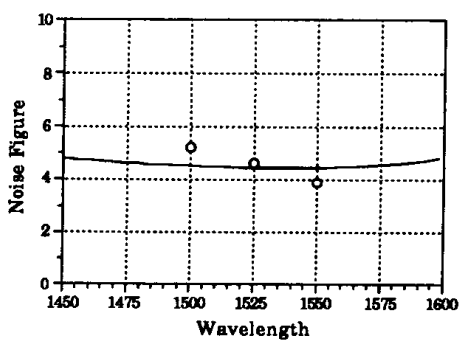

Fig. 3 Noise figure versus wavelength for 4well MQW-SOA. 


\section{Applications}

The SOAs are inherently nonlinear when driven into saturation. Therefore their use as repeaters in multichannel systems will be restricted. They do however have a potential as boosters in transmitters and as preamplifiers in receivers. In the latter case the input signals to the SOAs will be weak and nonlinearities are not a problem. Promising results for a SOA-preamplifier in a 16-channel grating demultiplexer receiver have been reported [14]. Booster and preamplifier applications will especially become attractive as the SOAs are monolithically integrated.

Because of the relatively short lifetime $(<1 \mathrm{nsec})$ of the injected carriers the SOAs may be used for fast signal processing. Recent results for such applications are given in the following.

\section{Gates and switches}

One of the most important applications of SOAs could be as gates in high speed switching circuits where the light is controlled by simply modulating the injection current. As the switching time should preferably be comparable or shorter than a bit period the demands are high considering $\mathrm{Gb} / \mathrm{s}$ data rates. Encouraging results have already been obtained for the M-DCPBH structure (Fig. 1a) which show switching times of 155 and 186 psec for turn-on and turn-off with a driving current of only $100 \mathrm{~mA}$ [4].

Optically controlled gates can also be realized. One ex-
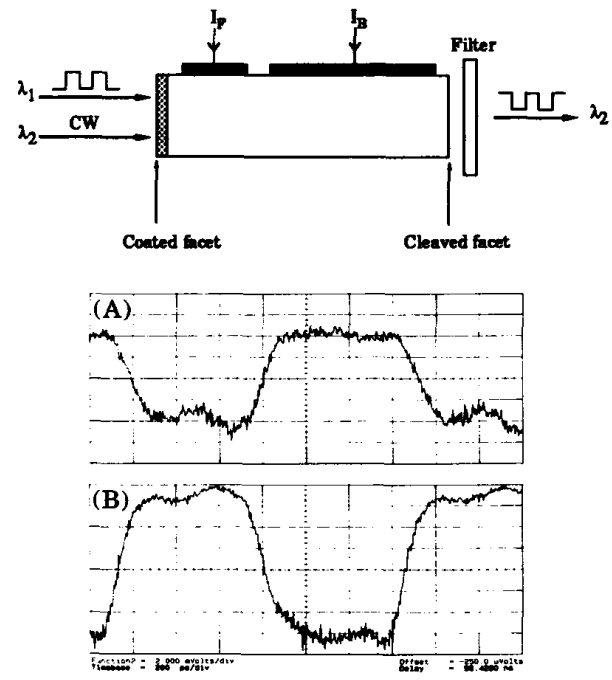

Fig. 4 Schematic of optically controlled two-section gate and example of control signal (B) and gated signal (A) (time scale: $200 \mathrm{psec} / \mathrm{div}$ ). ample is the two-section SOA shown in Fig. 4. Gating is achieved by saturating the amplifier with light at a wavelength $\left(\lambda_{1}\right)$ different from the signal wavelength $\left(\lambda_{2}\right)$. As seen, switching times of $\sim 150$ psec are achieved [15]. Only $-12 \mathrm{dBm}$ of optical power is needed for the control signal since the saturation power of the SOA is low due to the high reflectivity of the cleaved output facet.

Note that the optically controlled gate in Fig. 4 at the same time can be used as a wavelength converter that permits the signal to be shifted up to $-50 \mathrm{~nm}$. Electronically controlled 4-electrode wavelength converters, which requires only one optical input, can also be realized [16] but they operate in a more narrow bandwidth.

\section{Phase modulators}

SOAs can be used as phase modulators since the refractive index of the material is dependent on the injected carrier concentration, which again depends on the injection current [17]. Typically, a phase modulation of $\pi$ radians is obtained for a modulation voltage of 1 Volt p-p. The natural modulation bandwidth is $0.5-1 \mathrm{GHz}$ and is determined by the carrier lifetime. If larger modulation bandwidths are needed the response of the SOA can be equalized up to $2.5 \mathrm{GHz}$.

The SOA phase modulators exhibit unwanted amplitude modulation. This can, however, be reduced with two-section SOAs where the two sections are operated with different carrier concentrations and are modulated out of phase [18]. An example of the ratio between phase and amplitude modulation indices $(\beta / \mathrm{m})$ is seen in Fig. 5 as a function of the modulation power to the back section. Clearly the amplitude modulation can be virtually eliminated. Two-section SOAs may also be used for chirp-free amplitude modulation.

\section{Detection}

SOAs can also be used as detectors because the voltage

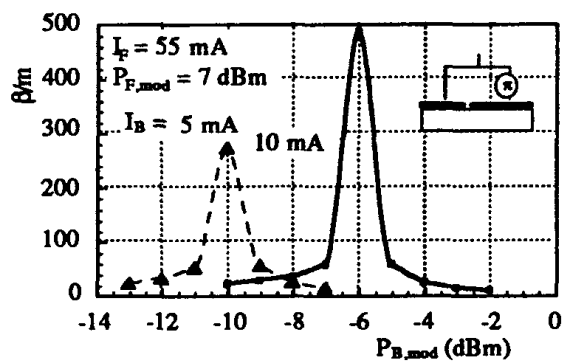

Fig. 5 Ratio between phase and amplitude modulation for two-section SOA phase modulator. 
across the pn-junction (quasi-Fermi levels) depends on the carrier density, which again interacts with the optical input signal [19]. With the SOAs biased to $20 \mathrm{~dB}$ of internal gain, responsivities of the order of $250 \mathrm{mV} / \mathrm{mW}$ can be obtained. This is sufficient for many applications and makes SOAs attractive as transparent channel drops.

Some advantages can be gained by using a two-section SOA since the first section can amplify the signal while the back section is used for detection. In this case the responsivity can be increased $\sim 30$ times compared to the single-section SOA [20].

\section{Conclusion}

SOAs are under rapid development to achieve polarization independent gain, low facet reflectivities, good coupling to optical fibers and high saturation power. The packaged SOA can be made compact and possibly inex- pensive, but its main advantage is the potential for optoelectronic integration.

SOAs may be used as booster and preamplifiers, but in case of multichannel systems attention must be given to the inherent nonlinear behavior that is due to the short lifetime of the injected carrier density. The short lifetime will on the other hand allow SOAs to be used as gates, modulators, detectors and frequency converters for signals with $\mathrm{Gbit} / \mathrm{s}$ data rates.

\section{Acknowledgment}

A part of the presented results has been obtained in RACE project 1027. We thank Drs. P.G. Dawe, S. Bland and J. King of BNR Europe, Harlow, Drs. B. Fernier and B. Mersali of Alcatel Alsthom Recherche, Marcoussis and Drs. J.C. Simon and C. Vassalo of CNET, Lannion for allowing us to show some of their results.

\section{References}

[1] N.A. Olsson et al., "Polarisation independent optical amplifier with buried facets", Electron. Lett., Vol. 25, pp. 1048-1049, 1989.

[2] I. Cha et al., " $1.5 \mu \mathrm{m}$ band travelling wave semiconductor optical amplifiers with window facet structure", in Techn. Digest of IOOC '89, Vol. 3, pp. 150151, Kobe, July 1989.

[3] B. Mersali et. al., "1.55 $\mu \mathrm{m}$ high-gain polarisationinsensitive semiconductor travelling-wave amplifier with low driving current", Electron. Lett., Vol. 26, pp. 124-125, 1990.

[4] B. Fernier, Alcatel Alsthom Rech., private communication.

[5] P.J.G. Dawe, BNR Europe, private communication.

[6] A.J. Collar et al., "Low residual reflectivity of angled-facet semiconductor laser amplifiers", IEEE Photonics Techn. Lett., Vol. 2, pp. 553-555, 1990.

[7] J.C. Simon, CNET Lannion, private communication.

[8] S. Tsuji et al., "18-dB fiber to fiber gain in packaged semiconductor laser amplifiers", in Techn. Dig. on Optical Amplifiers and Their Applications, Monterey, Calif., Aug. 1990, pp. 74-77.

[9] U. Koren et al., "Wavelength division multiplexing light source with integrated quantumwell tuneable lasers and optical amplifiers", Appl. Phys. Lett, Vol. 54, pp. 2056, 1989.

[10] M. Janson et al., "Monolithically integrated $2 \times 2$ InGaAsP/InP laser amplifier gate switch arrays", in Proc. of ECOC '91, Vol. 3, pp. 28-31, Paris, Sept. 91.

[11] D.M. Cooper et al., "Broadband operation of InGaAsP-InGaAs GRINSCH-MQW amplifiers with $115 \mathrm{~mW}$ saturated output power", in Techn. Dig. of OFC '90, paper PD32, San Fransisco, Jan. 1990.
[12] N.A. Olsson, "Lightwave systems with optical amplifiers", J. Lightwave Technol., Vol. LT-7, pp. 1071-1082, 1989.

[13] K. Magari et al., "1.55 $\mu \mathrm{m}$ polarization-insensitive high-gain tensile-strained-barrier MQW optical amplifier", IEEE Photon. Technol. Lett., Vol. 3, pp. 998-1000, Nov. 1991.

[14] J.P. King et al., "An optically preamplified $1 \mathrm{~Gb} / \mathrm{s}$ per channel multichannel grating demultiplexer receiver", in Techn. Dig. on Optical Amplifiers and Their Applications, Snowmass, Col.., July 1991, pp. 226-229.

[15] T. Durhuus, B. Fernier et al., "High speed all-optical gating using two section semiconductor optical amplifier structure", to be presented at CLEO '92, Anaheim, May 1992.

[16] S. Yamakoshi et al., "An optical-wavelength conversion laser with tuneable range of $30 \AA^{\prime \prime}$, in Techn. Dig. of OFC '88, New Orleans, post deadline paper PD 10, Jan. 1988.

[17] G. Grosskopf et al., "Characteristics of semiconductor laser optical amplifier as phase modulator", Electron. Lett., Vol. 25, pp. 1188-1189, Aug. 1989.

[18] T.N. Nielsen et al., "Pure phase modulation by use of a two-electrode semiconductor optical amplifier", in Technical Digest of Optical Amplifiers and Their Applications, post deadline paper PdP8, Snowmass, Colorado, July 1991.

[19] M. Gustavsson et al., "Travelling wave semiconductor amplifier detectors", Jour. Lightwave Technol. Vol. 8, pp. 610-617, 1990.

[20] C. Joergensen et al., "Two section semiconductor optical amplifier used as an efficient channel dropping node", to be pub. in IEEE Photon. Technol. Lett. 